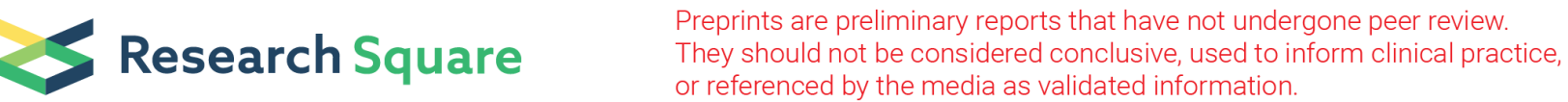 \\ Focus on renal blood flow in mechanically ventilated patients with SARS-CoV-2
}

\author{
Alberto Fogagnolo \\ Sant'Anna Hospital https://orcid.org/0000-0002-2737-0162
}

\section{Salvatore Grasso}

Università degli Studi di Bari "Aldo Moro" https://orcid.org/0000-0002-0287-0232

\section{Martin Dres}

Neurophysiologie respiratoire expérimentale et clinique https://orcid.org/0000-0001-9191-6089

\section{Loreto Gesualdo}

Università degli Studi di Bari "Aldo Moro" https://orcid.org/0000-0002-4861-0911

\section{Elena Morelli}

Sant'Anna Hospital

Irene Ottaviani

Sant'Anna Hospital

Elisabetta Marangoni

Sant'Anna Hospital https://orcid.org/0000-0002-9081-9946

Carlo Alberto Volta ( $\nabla$ vlc@unife.it)

Sant'Anna Hospital https://orcid.org/0000-0003-3533-6121

Savino Spadaro ( $\square$ savinospadaro@gmail.com )

Sant'Anna Hospital https://orcid.org/0000-0001-5027-5318

\section{Research Article}

Keywords: ARDS, COVID-19; SARS-CoV-2, Coronavirus, mechanical ventilation, renal resistivity index, acute kidney injury

Posted Date: August 19th, 2020

DOI: https://doi.org/10.21203/rs.3.rs-57589/v1

License: (c) (1) This work is licensed under a Creative Commons Attribution 4.0 International License. Read Full License 


\section{Abstract}

Background: Patients with ARDS due to the severe acute respiratory syndrome coronavirus-2 (SARS-CoV2) seem particularly susceptible to AKI. Our hypothesis was that the renal blood flow could be more compromised in SARS-CoV-2 patients than in patients with "traditional" ARDS. We compared the renal resistivity index (RRI) and the renal venous flow (RVF) in ARDS patients with SARS-CoV-2 and in ARDS patients due to other etiologies.

Materials and Methods: Prospective, observational study performed on 30 mechanically ventilated patients (15 with SARS-COV-2 ARDS and 15 with ARDS). Ultrasound Doppler measurements of RRI and RVF pattern were performed in each patient.

Results: Patients with SARS-COV-2 ARDS had higher RRI than patients with ARDS (0.71[0.67-0.78] vs $0.64[0.60-0.74], p=0.04)$. RVF was not-continuous in $9 / 15$ patients $(71 \%)$ in the SARS-COV-2 ARDS group and in and $5 / 15(33 \%)$ in the ARDS group $(p=0.27)$. A linear correlation was found between PEEP and RRI in patients with SARS-COV-2 ARDS $\left(r^{2}=0.31 ; p=0.03\right)$ but not in patients with ARDS. Occurrence of AKI was $53 \%$ in patients with SARS-COV-2 ARDS and $33 \%$ in patients with ARDS $(p=0.46)$.

Conclusions: We found a more pronounced impairment in renal blood flow in mechanically ventilated patients with SARS-COV-2 ARDS, compared with patients with "traditional" ARDS.

\section{Introduction}

The occurrence of acute kidney injury (AKI) in mechanically ventilated patients with acute respiratory distress syndrome (ARDS) due to the novel severe acute respiratory syndrome coronavirus 2 (SARS-CoV2) ranges between 15 and $23 \%$ being as high as $50 \%$ in non-survivors. [1,2] Besides COVID-19 may per se induce a kidney disease, [3] mechanical ventilation could play a role. Recent guidelines recommend the use of lung-protective mechanical ventilation in ARDS, consisting in low tidal volumes and relatively high levels of positive end-expiratory pressure (PEEP). [4] although this strategy could have a relevant hemodynamic impact. $[5,6]$ In particular, positive pressure ventilation associated with relatively high PEEP levels has been shown to increase arterial resistances and decrease venous return, leading to glomerular congestion and increase in kidney interstitial hydrostatic pressures. [5-8] Furthermore, it seems that in SARS-COV-2 ARDS respiratory system compliance $\left(\mathrm{C}_{\mathrm{RS}}\right)$ is atypically high compared to the degree of arterial hypoxemia, [9-10] and this could lead to even more pronounced impact of PEEP on systemic and renal perfusion. [9-10] This mechanism of impairing renal function should be considered as additional to the kidney damage due to COVID-19 infection by itself. [3] It might be then hypothesized that the levels of PEEP needed in patients with COVID-19 infection could result in greater extent of kidney damage compared to those patients with ARDS due to different etiologies. Hence the aim of our study was to document a potential different involvement of the kidney function by evaluating the degree of renal blood flow impairment in SARS-COV-2 ARDS compared to those with the "classic" ARDS. Accordingly, we performed an ultrasound evaluation of the renal resistivity index (RRI) and renal venous flow pattern 
(RVF) [11-13] in two groups of patients, i.e. with SARS-COV-2 ARDS and with ARDS, ventilated with the same lung-protective protocol.

\section{Materials And Methods}

\section{Population}

Prospective, observational study performed in a COVID-19 Intensive Care Unit (ICU) and a mixed medicalsurgical ICU at University Hospital of Ferrara, Italy. The study was approved by the ethic committee (approval number 339/2020). We included consecutive patients with SARS-COV-2 ARDS or ARDS undergoing mechanical ventilation. Exclusion criteria were: diagnosis of AKI before ICU admission, unsatisfactory ultrasound visualization, arrhythmia, renal replacement therapy and denied consent. All patients included in the SARS-COV-2 ARDS group had laboratory-confirmed COVID-19.

\section{Mechanical ventilation settings}

At the time of renal blood flow assessment, all patients were deeply sedated and paralyzed with continuous infusion of cis-atracurium $1-3 \mathrm{mcg} / \mathrm{kg} / \mathrm{min}$ for clinical reasons. Mechanical ventilation settings included constant-flow controlled ventilation, a tidal volume of $6 \mathrm{ml} / \mathrm{kg}$ of ideal body weight and the PEEP level titrated to the lowest driving pressure. [14] Briefly, PEEP was increased by $2 \mathrm{cmH}_{2} \mathrm{O}$ step starting from $6 \mathrm{cmH}_{2} \mathrm{O}$, up to the PEEP level leading to a static end-inspiratory plateau pressure (P PLAT) of 28-30 $\mathrm{cmH}_{2} \mathrm{O}$; then, the PEEP level corresponding to the lowest driving pressure was chosen.

The driving pressure was measured as:

$\mathrm{P}_{\text {PLAT }}-\mathrm{PEEP}_{\text {TOT }}$

Where PEEP TOT $_{\text {is }}$ the total static positive end-expiratory pressure. $\mathrm{P}_{\mathrm{PLAT} \text { and }}$ PEEP $_{\text {TOT }}$ were measured through the occlusion technique (i.e. a 4 sec airway opening occlusion maneuver at end-inspiration and end-expiration, respectively)

\section{Renal blood flow assessment}

Ultrasound evaluation of renal blood flow was performed within 24 hours from starting of MV. All the measurements were taken on the right kidney with the patient in semi-recumbent position (30 degrees), through a posterolateral approach. Color Doppler images were used to identify the interlobar vessels. An interlobar or arcuate artery was selected for pulse wave Doppler measurements and RRI was calculated as:

peak systolic velocity-end diastolic velocity/peak systolic velocity.

An RRI $>0.7$ was deemed pathological. [11-13] 
The RVF pattern was classified as continuous, biphasic or monophasic. [11] Under physiological conditions, the RVF pattern is continuous, whereas during renal congestion it becomes biphasic or even monophasic. [11]

For both RRI and RVF three measurements were obtained over 3 cardiac cycles and the mean value was recorded for analysis.

\section{Secondary outcomes}

The occurrence of AKI, as well as need for renal replacement therapy (RRT), was recorded. Further, we investigated the ability of RRI to predict the occurrence of AKI and the need of RRT. AKI was defined according to the Kidney Disease: Improving Global Outcomes (KDIGO) guidelines as an increase in serum creatinine of $0.3 \mathrm{mg} / \mathrm{dL}$ within $48 \mathrm{~h}$, an increase in serum creatinine to 1.5 times the baseline value present within the previous 7 days, or a urinary output $<0.5 \mathrm{~mL} / \mathrm{kg} / \mathrm{h}$ for 6 hours. [15] Indications for RRT were serum urea $>150 \mathrm{mg} / \mathrm{dL}$, severe hyperkalemia (over $6 \mathrm{mmol} / \mathrm{L}$ or with sign of electrocardiogram abnormalities), urine output $<200 \mathrm{~mL} /$ die, fluid overload despite diuretic treatment. [16]

\section{Statistical analysis}

Categorical data are presented as frequencies and percentages, while continuous variables as mean \pm standard deviation or medians with interquartile range, as appropriate. The Shapiro-Wilk test was used to assess the assumption of normality. Categorical data were compared using the $\chi 2$ test or Fisher exact test as appropriate. Mann-Whitney $U$ tests was used to compare continuous variables. Pearson correlation with $\mathrm{R}$ square was used to analyze the correlation. Receiver operator characteristic (ROC) curves were used to analyze the ability of RRI to predict AKI. ROC curve analyses are reported as AUROC with $95 \%$ confidence interval $(95 \% \mathrm{Cl})$. Optimal cut-off scores were determined using Youden's Index. Differences in repeated measurements in the two groups were analyzed using Friedman's rank analysis. Statistical analyses were performed using SPSS 25.0 statistical software (SPSS Inc., Chicago, IL). For each statistical test a 2-tailed test was performed and a p value of 0.05 was considered statistically significant.

\section{Sample size}

Due to the lack of clinical study in this field, we were unable to perform an accurate power analysis. Nonetheless, using the upper confidence interval for the population variance approach to the sample size calculation a pilot sample size between 20 and 40 correspond to standardized effect sizes of 0.4 and 0.7 (for $90 \%$ power based on a standard sample size calculation). According to this issue, 30 patients ( 15 for each group) were included in the study.

\section{Results}

Population and renal blood flow evaluation 
The renal blood flow evaluation was performed after 1 [0-1] days of MV. As shown in Table 1, compared with patients with ARDS, patients with SARS-COV-2 ARDS had higher RRI (0.71 [0.67-0.78] vs 0.64 [0.60 - 0.74], p=0.04). (Figure 1) In patients with SARS-COV-2 ARDS, but not in patients with ARDS, there was a linear correlation between PEEP and RRI $\left(r^{2}=0.31 ; p=0.03\right)$ (Figure 2). The RVF was not-continuous in 9/15 patients $(71 \%)$ in SARS-COV-2 ARDS group and 5/15 (33\%) in not-CoV-2 ( $p=0.27)$.

\section{Secondary outcomes}

AKI occurred in 8/15 of patients (53\%) in SARS-COV-2 ARDS and in 5/15 (33\%) in ARDS ( $p=0.46)$. AKI was detected after 2 [1-2] days (range 1-4) from renal blood flow evaluation. Four patients (4/15, 27\%) in SARS-COV-2 ARDS group needed RRT versus one in the ARDS group (1/15, 6\%; $p=0.33)$. Additional data regarding SARS-COV-2 ARDS patients are given in Table S1 and Figure S1. In particular, SARS-COV-2 ARDS patients with AKI were more likely to experience a subsequent impairment in respiratory system compliance (Figure S1). Taking into account the whole population, patients who developed AKI had higher RRI $(0.77$ [0.73-0.80] vs 0.66 [0.60-0.69]; $p=0.001)$ as well as higher percentage of impaired RVF (13/13 vs $1 / 17 ; p<0.001)$. The RRI was associated with the subsequent occurrence of AKI (AUROC 0.938 [0.93-0.99]; $p<0.001)$. The Youden index analysis showed that RRI>0.71 was the best cut-off value to predict AKI, with $90 \%$ sensitivity and $100 \%$ specificity. The RRI was also a predictor for RRT (AUROC=0.896 [0.73 - 0.98]; best cut-off 0.77; sensitivity $80 \%$ specificity $92 \%$ ).

\section{Discussion}

The main finding of our study is that the renal blood flow is more compromised in mechanically ventilated patients with SARS-COV-2 ARDS than in patients with ARDS due to other etiologies.

The pathogenesis of renal dysfunction in patients with COVID 19 is multifactorial. [2,3,17] A recent observational study including 116 hospitalized patients shows that non ventilated patients with SARSCoV-2 pneumonia seldom develop AKI [18]; conversely, in studies including patients requiring respiratory support, incidence of AKI was up to 23\%. [1] Despite the increasing severity of the disease could explain these findings, positive pressure ventilation can also play an important role. [5-8]. The underlying mechanism could be the well-known impact of positive pressure on the renal blood flow. Mechanical ventilation could induce glomerular congestion, by increasing the pericardial pressure, leading to a critical increase in interstitial hydrostatic pressure [6-7], which increases arterial resistances [6-7]. Interestingly, Gattinoni and Marini suggested that the SARS-CoV-2 induced ARDS is as a peculiar ARDS form characterized by an atypically high respiratory system compliance $\left(C_{R S}\right)$, compared to the degree of arterial hypoxemia. [9-10,19-20] Since the hemodynamic effects of PEEP are enhanced at relatively higher $\mathrm{C}_{\mathrm{RS} \text {., }}$ [20-21] the hemodynamic impact of mechanical ventilation on kidney perfusion could be more pronounced in patients with SARS-CoV-2 ARDS than in patients with ARDS due to other etiologies. Our finding of a linear relationship between RRI and PEEP only in patients with SARS-CoV-2 ARDS (figure 2) seems to support this hypothesis, although we should point out that our study was not specifically designed to document the impact of PEEP on renal blood flow. 
Our results confirm the role of RRI and RVF in predicting occurrence of AKI. The RRI evaluation has gained importance in last years to monitor renal perfusion and to predict the occurrence of AKI, [11-13,22] as well as its severity. [23] Indeed, the genesis of kidney injury includes intrarenal vasoconstriction and endothelial damage of the micro-vessels which lead to impaired macro- and microvascular flow, both causes of increased RRI. [22,23] On the other hand, the RVF pattern is able to identify the occurrence of glomerular congestion, which is an additional cause of renal blood flow impairment [11]. High RRI values have been associated with the need for vasopressor support, hypotension and lactate levels [12], whereas non-continuous RVF have been described in the context of increased pulmonary wedge pressure [11]. We have also showed that high RRI values are common in patients undergoing lung-protective mechanical ventilation, regardless of the need of vasopressor or the presence of hyperlactacidemia.

Our study has some limitations. First, the small sample size could limit the interpretation of our results and does not account for covariate adjustment. Second, our study was not designed to separate between the different mechanism that could explain the impairment of renal blood flow. Nonetheless, the correlation between PEEP levels and RRI seems to suggest a possible role of mechanical ventilation in the RRI impairment.

\section{Conclusions}

In conclusion, we showed that during lung-protective mechanical ventilation, the renal blood flow is more impaired in patients with SARS-CoV-2 ARDS than in patients with ARDS due to other etiologies. Our findings suggest to carefully assess renal blood flow and even subtle signs of AKI in patients with SARSCoV-2 ARDS requiring mechanical ventilation. Further studies are needed to assess the specific role of mechanical ventilation in the pathogenesis of the SARS-CoV-2 ARDS kidney perfusion impairment and, eventually, if different approaches to PEEP setting could better preserve renal perfusion.

\section{What is known:}

- AKI is common in patients with SARS-CoV-2 ARDS

- Lung protective ventilation may impair renal blood flow

- Kidney doppler ultrasound allows the evaluation of renal resistivity index

\section{What is new:}

- Renal blood flow is more compromised in SARS-CoV-2 ARDS than in "traditional" ARDS.

- PEEP-induced impairment in renal blood flow might be higher in SARS-CoV-2 ARDS

- Ultrasound evaluation of renal blood flow is able to predict AKI in mechanically ventilated patients

\section{Declarations}

\section{Competing Interests}


The authors have no competing interests.

\section{Ethics Approval}

The study was approved by our ethic committee (approval number 339/2020).

All patients gave written consent to the study; for patients unable to give, the consent was taken by next of kin and delayed consent was given by patient if he became able to give.

\section{Funding}

This study was financially supported by the University of Ferrara, Ferrara, Italy

\section{Author contributions}

FA, VCA and SS was involved in the conception and the design of the study, analyzed the data and wrote the paper. FA and ME collected the data. FA performed the statistical work. VCA and SS were involved in the conception and the design of the study. MD and GS and LG contributed to analysis of the data and critical revision of the manuscript for important intellectual content. All authors reviewed the manuscript and agreed with the final version.

\section{Abbreviations}

ARDS: acute respiratory distress syndrome; SARS-CoV-2: acute respiratory syndrome coronavirus 2; MV: mechanical ventilation; RRI: renal resistivity index; RVF: renal venous flow pattern; KDIGO: Kidney Disease: Improving Global Outcomes; RRT: renal replacement therapy; ROC: Receiver operator characteristic;

\section{References}

1. Yang X, Yu Y, Xu J, Shu H, Xia J, Liu H et al. Clinical course and outcomes of critically ill patients with SARS-CoV-2 pneumonia in Wuhan, China: a single-centered, retrospective, observational study. Lancet Respir Med. 2020 E-pub ahead of printing.

2. Pei G, Zhang Z, Peng J, Liu L, Zhang C, Yu C et al. Renal Involvement and Early Prognosis in Patients with COVID-19 Pneumonia. J Am Soc Nephrol. 2020 E-pub ahead of printing.

3. Cheng Y, Luo R, Wang K, Zhang M, Wang Z, Dong L et al. Kidney disease is associated with inhospital death of patients with COVID-19. Kidney International 2020; 5, $829-838$

4. Poston JT, Patel BK, Davis AM. Management of Critically III Adults With COVID-19. JAMA 2020. Epub ahead of printing

5. Vieillard-Baron A, Loubieres Y, Schmitt JM, Page B, Dubourg O, Jardin F: Cyclic changes in right ventricular output impedance during mechanical ventilation. J Appl Physiol 1999, 87:1644-1650. 
6. Joannidis M, Forni LG, Klein SJ, Honore PM, Kashani K, Ostermann M et al. Lung-kidney interactions in critically ill patients: consensus report of the Acute Disease Quality Initiative (ADQI) 21 Workgroup. Intensive Care Med. 2020; 46(4):654-672.

7. Panitchote A, Mehkri O, Hastings A, Hanane T, Demirjian S, Torbic $\mathrm{H}$ et al. Factors associated with acute kidney injury in acute respiratory distress syndrome. Ann Intensive Care. 2019;9(1):74.

8. Gurkan OU, O’Donnell C, Brower R, Ruckdeschel E, Becker PM. Differential effects of mechanical ventilatory strategy on lung injury and systemic organ inflammation in mice. Am J Physiol Lung Cell Mol Physiol 2005; 285:L710-718

9. Grasselli G, Zangrillo A, Zanella A, Antonelli M, Cabrini L, Castelli A et al. Baseline Characteristics and Outcomes of 1591 Patients Infected With SARS-CoV-2 Admitted to ICUs of the Lombardy Region, Italy. JAMA. 2020;323(16):1574-1581.

10. Gattinoni, L., Chiumello, D., Rossi, S. COVID-19 pneumonia: ARDS or not?. Crit Care 2020; 24, 154

11. Husain-Syed F, Birk HW, Ronco C, Schörmann T, Tello K, Richter MJ. Doppler-Derived Renal Venous Stasis Index in the Prognosis of Right Heart Failure. J Am Heart Assoc. 2019; 8(21):e013584.

12. Oliveira RAG, Mendes PV, Park M, Taniguchi LU. Factors associated with renal Doppler resistive index in critically ill patients: a prospective cohort study. Ann Intensive Care 2019; 9(1):23.

13. Dewitte A, Coquin J, Meyssignac B, Joannès-Boyau O, Fleureau C, Roze H, et al. Doppler resistive index to reflect regulation of renal vascular tone during sepsis and acute kidney injury. Crit Care. 2012;16(5):R165.

14. Pereira Romano ML, Maia IS, Laranjeira LN, Damiani LP, Paisani DM, Borges MC. Driving PressureLimited Strategy for Patients with Acute Respiratory Distress Syndrome (ARDS): A Pilot Randomized Clinical Trial. Ann Am Thorac Soc. 2020 E-pub ahead of printing.

15. Khwaja A. KDIGO clinical practice guidelines for acute kidney injury. Nephron Clin Pract 2012; 120: c179-84

16. Bagshaw SM, Cruz DN, Gibney RT, Ronco C. A proposed algorithm for initiation of renal replacement therapy in adult critically ill patients. Crit Care 2009; 13, 317

17. Su H, Yang M, Wan C, Yi LX, Tang F, Zhu HY et al. Renal histopathological analysis of 26 postmortem findings of patients with COVID-19 in China. Kidney Int. 2020 E-pub ahead of printing.

18. Wang L, Li X, Chen H, Yan S, Li D, Li Y. Coronavirus Disease 19 Infection Does Not Result in Acute Kidney Injury: An Analysis of 116 Hospitalized Patients from Wuhan, China. Am J Nephrol. 2020 Mar 31:1-6.

19. Marini JJ, Gattinoni L. Management of COVID-19 Respiratory Distress. JAMA. 2020. E-pub ahead of printing.

20. Gattinoni, L., Chiumello, D., Caironi, P, Busana M, Romitti F, Brazzi L et al. COVID-19 pneumonia: different respiratory treatments for different phenotypes? Intensive Care Med 2020 E-pub ahead of printing. 
21. Chen X, Wang X, Honore PM, Spapen HD, Liu D. Renal failure in critically ill patients, beware of applying (central venous) pressure on the kidney. Ann Intensive Care. 2018;8(1):91.

22. Garnier F, Daubin D, Larcher R, Bargnoux AS, Platon L, Brunot V. Reversibility of Acute Kidney Injury in Medical ICU Patients: Predictability Performance of Urinary Tissue Inhibitor of Metalloproteinase-2 $x$ Insulin-Like Growth Factor-Binding Protein 7 and Renal Resistive Index. Crit Care Med. 2020 (4):e277e284.

23. Haitsma Mulier JLG, Rozemeijer S, Röttgering JG, Spoelstra-de Man AME, Elbers PWG, Tuinman PR et al. Renal resistive index as an early predictor and discriminator of acute kidney injury in critically ill patients; A prospective observational cohort study. PLoS One. 2018; 13(6): e0197967.

24. Gomez H, Ince C, De Backer D, Pickkers P, Payen D, Hotchkiss J, et al. A Unified Theory of SepsisInduced Acute Kidney Injury. Shock. 2014;41: 3-11

\section{Tables}




\begin{tabular}{|c|c|c|c|c|}
\hline Variables & $\begin{array}{l}\text { All patients } \\
\mathrm{n}=30\end{array}$ & $\begin{array}{l}\text { SARS-CoV-2 ARDS } \\
n=15\end{array}$ & $\begin{array}{l}\text { ARDS } \\
n=15\end{array}$ & $\begin{array}{l}\mathrm{P} \\
\text { value }\end{array}$ \\
\hline Age & $64[60-72]$ & $62[55-69]$ & $67[62-74]$ & 0.89 \\
\hline $\operatorname{Sex}(F / M)$ & $5 / 25$ & $2 / 13$ & $3 / 12$ & 0.99 \\
\hline SOFA score at ICU admission & 8 [5 -10] & $6[4-10]$ & $9[8-10]$ & 0.05 \\
\hline Need for vasopressor, n (\%) & $12(40)$ & $5(33)$ & $7(46)$ & 0.71 \\
\hline \multicolumn{5}{|l|}{ Comorbidities } \\
\hline Hypertension, n (\%) & $17(57)$ & $8(53)$ & $9(60)$ & 0.71 \\
\hline CKD, n (\%) & $7(23)$ & $3(20)$ & $4(27)$ & 0.99 \\
\hline BMI >35 (kg/m²), n (\%) & $3(10)$ & $1(7)$ & $2(13)$ & 0.99 \\
\hline Diabetes, n (\%) & $6(20)$ & $3(20)$ & $3(20)$ & 0.99 \\
\hline \multicolumn{5}{|l|}{ Reasons for ICU admission } \\
\hline Septic shock & 4 & $4(27)$ & / & 0.09 \\
\hline ARDS & 26 & $11(73)$ & 15 & 0.09 \\
\hline \multicolumn{5}{|l|}{$\begin{array}{l}\text { Laboratory data at ICU } \\
\text { admission }\end{array}$} \\
\hline Hemoglobin $(\mathrm{g} / \mathrm{dL})$ & $\begin{array}{l}11.0[9.8- \\
13.6]\end{array}$ & $10.9[9.6-12.4]$ & $\begin{array}{l}12.8[9.9- \\
13.6]\end{array}$ & 0.49 \\
\hline Platelets $\left(10^{9} / \mathrm{L}\right)$ & $\begin{array}{l}219[179- \\
302]\end{array}$ & $263[204-305]$ & $\begin{array}{l}208[143- \\
301]\end{array}$ & 0.19 \\
\hline Serum creatinine (mg/L) & $1.0[0.7-2.5]$ & $0.8[0.7-1.2]$ & $2.5[0.7-3.6]$ & 0.11 \\
\hline
\end{tabular}

Table 1. Clinical and demographical characteristics of patients at ICU admission. CKD: Chronic kidney disease; BMI: Body Mass Index; PEEP: Positive end-expiratory pressure; $\mathrm{PaCO}_{2}$ : arterial carbon dioxide tension 


\begin{tabular}{|c|c|c|c|}
\hline Variables & SARS-CoV- 2 ARDS $n=15$ & $\begin{array}{l}\text { ARDS } \\
n=15\end{array}$ & $P$ value \\
\hline \multicolumn{4}{|l|}{ Renal blood flow evaluation } \\
\hline Renal resistivity index & $0.71[0.67-0.78]$ & $0.64[0.60-0.74]$ & 0.04 \\
\hline \multicolumn{4}{|l|}{ Renal venous flow pattern } \\
\hline Continuous & $6(40)$ & $10(66)$ & 0.27 \\
\hline Biphasic & $4(27)$ & $3(20)$ & 0.99 \\
\hline Monophasic & $5(33)$ & $2(14)$ & 0.40 \\
\hline \multicolumn{4}{|l|}{ Respiratory mechanics } \\
\hline Tidal volume $(\mathrm{mL})$ & $440[400-480]$ & $395[350-480]$ & 0.27 \\
\hline Respiratory rate & $18[18-22]$ & $18[16-20]$ & 0.14 \\
\hline Minute ventilation $(\mathrm{L} / \mathrm{m})$ & $7.9[7.2-9.0]$ & $7.4[6.0-8.6]$ & 0.10 \\
\hline Plateau pressure $\left(\mathrm{cmH}_{2} \mathrm{O}\right)$ & $22[22-24]$ & $21[18-24]$ & 0.11 \\
\hline PEEP $\left(\mathrm{cmH}_{2} \mathrm{O}\right)$ & 14 [12 - 14] & $10[10-12]$ & 0.004 \\
\hline Driving pressure $\left(\mathrm{cmH}_{2} \mathrm{O}\right)$ & $10[8-10]$ & $9[8-12]$ & 0.90 \\
\hline Static compliance $\left(\mathrm{ml} / \mathrm{cmH}_{2} \mathrm{O}\right)$ & $45[41-52]$ & $40[37-47]$ & 0.03 \\
\hline \multicolumn{4}{|l|}{ Hemodynamic parameters } \\
\hline Mean arterial pressure $(\mathrm{mmHg})$ & $75[70-80]$ & $82[67-91]$ & 0.21 \\
\hline Heart rate & $90[86-104]$ & $89[79-95]$ & 0.84 \\
\hline \multicolumn{4}{|l|}{ Blood gas analysis } \\
\hline $\mathrm{PaO}_{2} / \mathrm{FiO}_{2}(\mathrm{mmHg})$ & 118 [94 - 151] & $193[148-209]$ & 0.001 \\
\hline $\mathrm{PaCO}_{2}(\mathrm{mmHg})$ & $57[48-64]$ & $46[36-52]$ & 0.02 \\
\hline Lactate $(\mathrm{mmol} / \mathrm{L})$ & $1.2[1.2-1.6]$ & $2.2[1.1-3.2]$ & 0.13 \\
\hline
\end{tabular}

Table 2. Renal blood flow evaluation and respiratory mechanics in patients with C-ARDS and ARDS. SARS-CoV-2 ARDS: Coronavirus-induced ARDS; PEEP: Positive end-expiratory pressure; $\mathrm{PaCO}_{2}$ : arterial carbon dioxide tension

\section{Figures}




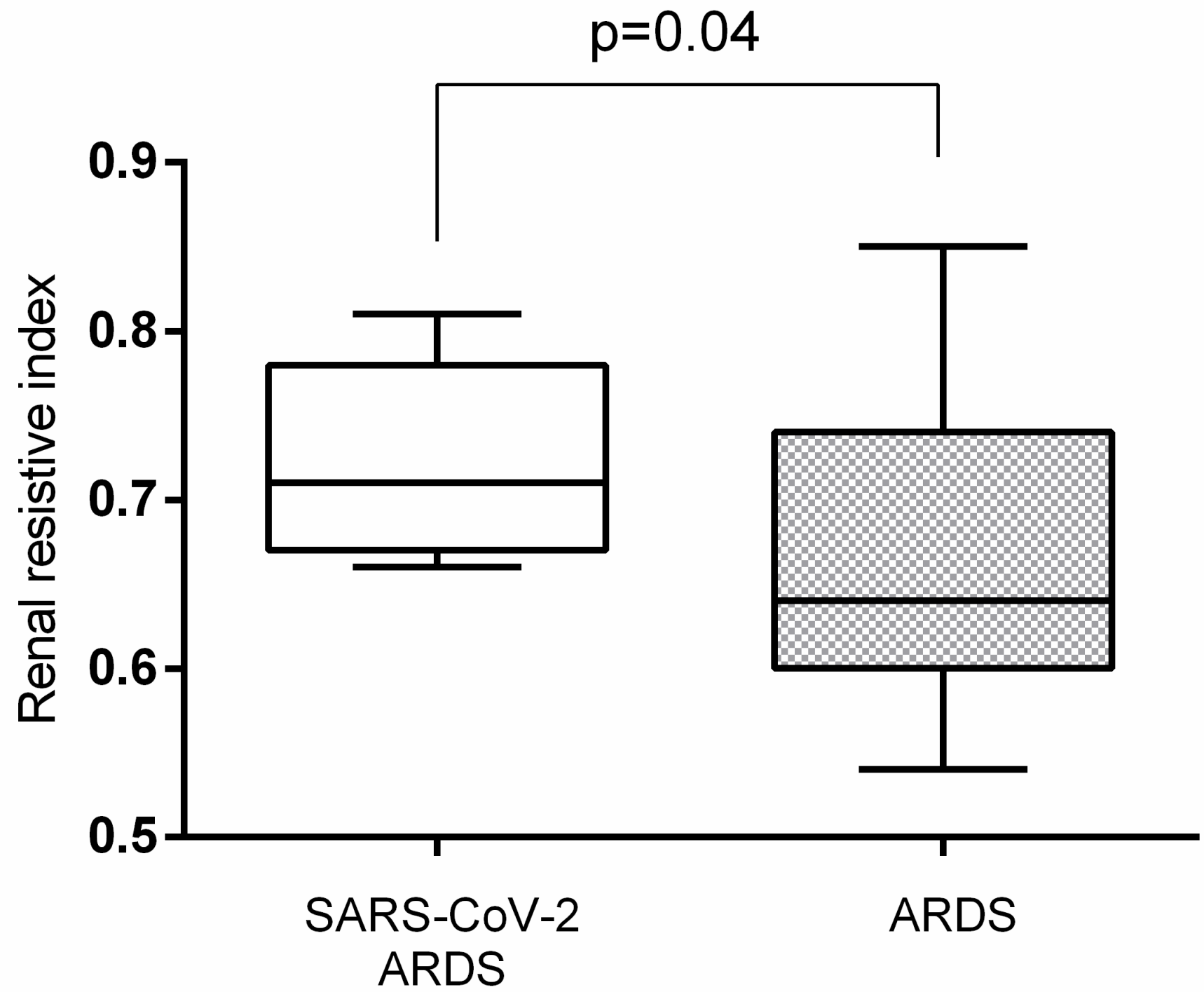

Figure 1

Comparison of renal resistivity index in patients with SARS-CoV-2 ARDS or ARDS. 


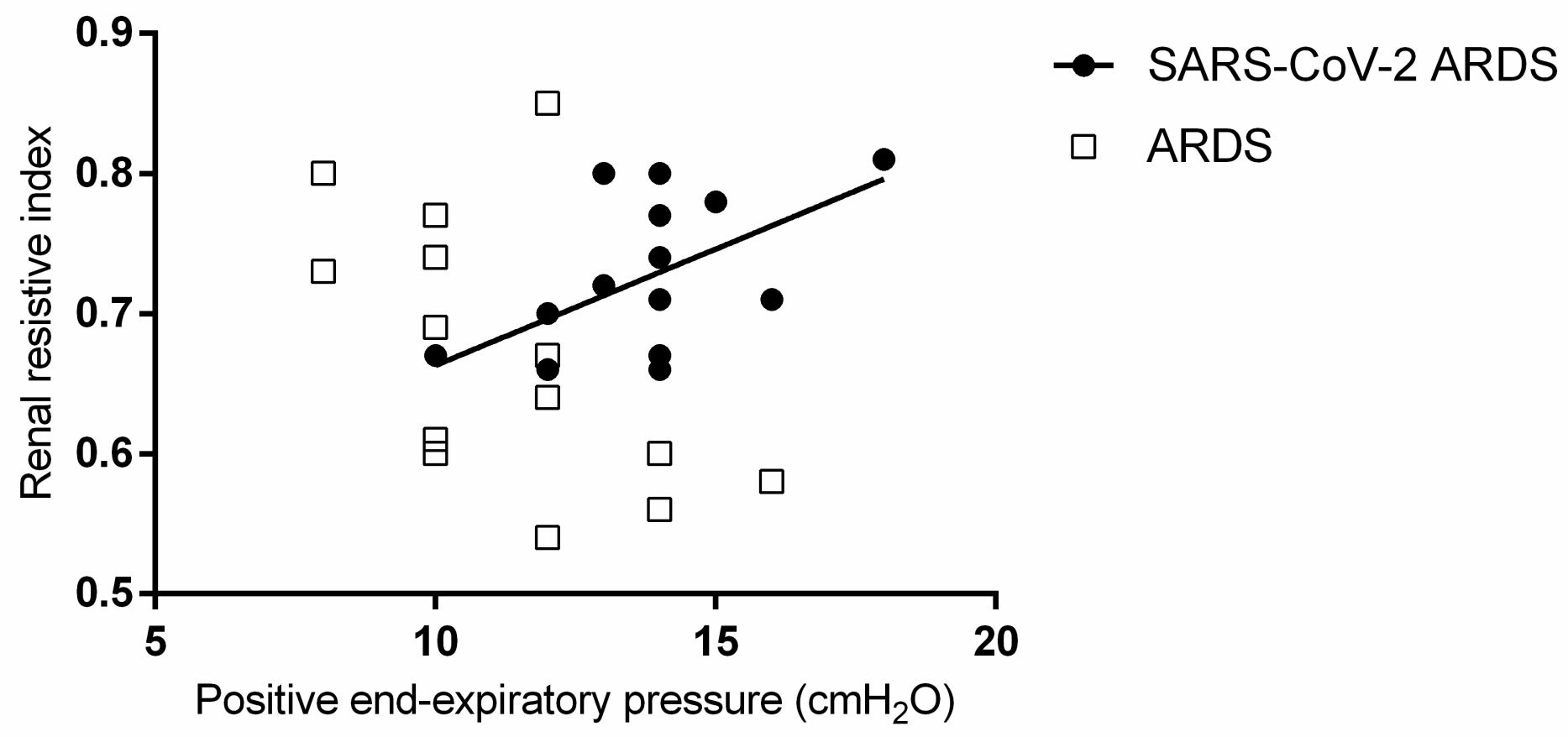

Figure 2

Correlation between PEEP level and renal resistivity index in patients with SARS-CoV-2 ARDS or ARDS.

\section{Supplementary Files}

This is a list of supplementary files associated with this preprint. Click to download.

- Figures1.tif

- TableS1.docx 